\title{
Researching Social Networks: Opportunities and Challenges
}

\author{
Dariusz Jemielniak* \\ MINDS (Management in Networked and Digital Societies) Department, Kozminski University, Warsaw, Poland
}

Keywords: online collaboration, collaborative society, citizen science, social movement, big data analysis, social network, peer production, thick data

New technologies have brought a number of new social phenomena, visible in peer production and open collaboration amongst others (Benkler and Nissenbaum, 2006; Levine and Prietula, 2013). The natural tendency to cooperate with others, typical for our species, has been amplified by new communication channels and platforms, resulting in the rapid growth of "collaborative society" (Jemielniak and Przegalinska, 2020).

The new social organization relies on novel kinds of structures: a-hierarchical or heterarchical large networks with little formal leadership. They are visible e.g., in the social organization of Wikipedia, the largest collaborative movement of humankind, openly rejecting traditional forms of organizing while relying on different, emergent communication, and decision-making patterns (Jemielniak, 2014; Shaw and Hargittai, 2018), as well as in other Free and Open Source (FOSS) initiatives (Lakhani and Von Hippel, 2003; Ciesielska, 2010; Chełkowski et al., 2016). It is worth mentioning that the new organizations, based on radically different social networks and division of work, can be very successful: Wikipedia is beyond any doubt the most popular encyclopedia in the world, Linux is the leading server operating system, Android is the dominant mobile phones operating system, etc.

Another example of new movements enabled by technology and new social networks is "citizen science": self-organized activists cooperate to make scientific discoveries or perform applied science

\section{OPEN ACCESS}

Edited and reviewed by:

Primavera De Filippi,

UMR7106 Centre d'Etudes et de Recherches de Sciences Administratives et Politiques (CERSA), France

*Correspondence: Dariusz Jemielniak dariusz.jemielniak@fulbrightmail.org

Specialty section:

This article was submitted to Social Networks,

a section of the journal Frontiers in Human Dynamics

Received: 20 January 2020 Accepted: 04 February 2020 Published: 25 February 2020

Citation: Jemielniak D (2020) Researching Social Networks: Opportunities and Challenges. Front. Hum. Dyn. 2:1 doi: 10.3389/fhumd.2020.00001 in ways that would typically not be accepted or done at traditional knowledge institutions (Lis and Stasik, 2017; Strasser et al., 2019). They successfully lead to independent actual innovations, as well as support the scientific community in its discoveries and exert social pressure on governments and municipalities, e.g., by monitoring smog or radiation and informing the larger public about the problem (Brown et al., 2016; Constant, 2018).

Similarly, new social movements online based on a remix culture result in a redefinition of creator-consumer boundaries (Hill and Monroy-Hernández, 2013; Milner, 2013). Even the communities formed around contemporary graphic meme consumption form specific ways of identity enactment, social bonding, gatekeeping and inclusion, often with a significant sociopolitical impact besides ironic entertainment (Silvestri, 2015; Huntington, 2016). In a much different, and yet somewhat similar area, blockchain technology and its network of participants are redefining how we deal with finance, contract validation, and data validity assurance, to name just a few (De Filippi, 2018).

Some more disturbing manifestations of new technologies and social networks are visible in the rise of anti-intellectual sentiments and the erosion of trust in social institutions in general and in science in particular (Pechar et al., 2018). We are facing an epistemic crisis (Dahlgren, 2018). Misinformation initiatives are able to spread through modern types of social networks and have a real impact (consider anti-vaxxers, human-induced climate change deniers and flat-Earthers) (Dahlstrom and Rosenthal, 2018; Samantray and Pin, 2019).

The new technologies bring major changes also to other key social phenomena: enactment of trust in society (Latusek and Vlaar, 2018), perception of ownership and commons (Kostakis, 2018; Hergueux and Jemielniak, 2019), expression of emotions and intimacy (Das and Hodkinson, 2019), or politics (Benkler et al., 2018; Chmielewska-Szlajfer, 2018), to mention just a few. Even the very 
primal rituals of how people choose life or sex partners have been radically affected by online dating networks (Alhabash et al., 2014; Rosenfeld, 2018). The landscape of social networks is getting more and more complicated also due to the rapid emergence of bots, as well as avatars increasingly differentiated from human representations (Przegalinska, 2015; Przegalinska et al., 2019).

These evolving phenomena, behaviors, and social structures already pose a significant challenge to social sciences. Yet, an even greater one comes from the fact that social networks and interactions online bring on absolute information and data overflow. As social scientists we are facing a paradox: never before in history have we had access to this much information about human behavior, and yet dealing with the oversupply is a problem in itself.

Naturally, access to troves of available data can also be a great opportunity (Conte et al., 2012; McCarthy, 2016; Lazer and Radford, 2017). It is not a coincidence that social sciences become datified (Millington and Millington, 2015), and that data scientists, or even physicists and software engineers make bold forays into the territory formerly reserved for sociologists, basically because of the data access.

The challenge, however, is that the data never speak for themselves (Dourish and Cruz, 2018). In fact, it is quite safe to assume that just relying on Big Data, especially without some deeper social network understanding may be very misleading. This is so not only because of the spurious correlations (Vigen, 2015) which may make even projects with such great promise as Google Flu fail miserably (Harford, 2014). Making sense of and from Big Data is simply very difficult (Hartung, 2018).

\section{REFERENCES}

Alhabash, S., Hales, K., Baek, J.-H., and Oh, H. (2014). J. Effects of race, visual anonymity, and social category salience on online dating outcomes. Comput. Hum. Behav. 35, 22-32. doi: 10.1016/j.chb.2014.02.016

Babones, S. (2016). Interpretive quantitative methods for the social sciences. Sociology 50, 453-469. doi: 10.1177/0038038515583637

Benkler, Y., Faris, R., and Roberts, H. (2018). Network Propaganda: Manipulation, Disinformation, and Radicalization in American Politics. Oxford: Oxford University Press.

Benkler, Y., and Nissenbaum, H. (2006). Commons-based peer production and virtue*. J. Polit. Philos. 14, 394-419. doi: 10.1111/j.1467-9760.2006.00235.x

Brown, A., Franken, P., Bonner, S., Dolezal, N., and Moross, J. (2016). Safecast: successful citizen-science for radiation measurement and communication after Fukushima. J. Radiol. Prot. 36, S82-S101. doi: 10.1088/0952-4746/36/2/S82

Chełkowski, T., Gloor, P. A., and Jemielniak, D. (2016). Inequalities in open source software development: analysis of contributor's commits in apache software foundation projects. PLoS ONE 11:e0152976. doi: 10.1371/journal.pone.0152976

Chmielewska-Szlajfer, H. (2018). Opinion dailies versus Facebook fan pages: the case of Poland's surprising 2015 presidential elections. Media Cult. Soc. 40, 938-950. doi: 10.1177/0163443718756065

Ciesielska, M. (2010). Hybrid Organisations. A Study of the Open Source - Business Setting. Copenhagen: Copenhagen Business School.

Constant, N. (2018). "Role of citizen science in air quality monitoring," in Urban Pollution, eds S. M. Charlesworth and C. A. Booth (New York, NY: John Wiley \& Sons), 303-312. doi: 10.1002/9781119260493.ch23
To mitigate these issues, some researchers propose to combine Big Data usage in social networks analysis with qualitative approaches (Halavais, 2015). Indeed, relying on qualitative insight allows adding context to quantitative datasets, which becomes particularly important when the datasets' raw power is overwhelming (Babones, 2016). This is why Thick Big Data, that is deeply quantitative analysis conducted in parallel with deeply interpretive one, is so attractive (Jemielniak, 2020). Yet, due to silosing and bunkerization typical for academia, most scientists specializing in Big Data are not proficient in ethnographic approaches and vice versa.

It is time to address these ambiguities. Our goal is addressing the new phenomena related to social networks, by relying on new forms of collecting and analyzing data, and by experimenting with novel and combined methodologies. We welcome a wide array of topics, challenging the current understanding of social science, bringing new knowledge about human behavior, both online and offline, in social networks of old and new types so that we discover new ways of conducting research on social networks, both in a quantitative and qualitative way.

\section{AUTHOR CONTRIBUTIONS}

The author confirms being the sole contributor of this work and has approved it for publication.

\section{FUNDING}

Working on this article was possible thanks to grant No. PPN/BEK/2018/1/00009 from the Polish National Agency for Academic Exchange.

Conte, R., Gilbert, N., Bonelli, G., Cioffi-Revilla, C., Deffuant, G., Kertesz, J., et al. (2012). Manifesto of computational social science. Eur. Phys. J. Spec. Top. 214, 325-346. doi: 10.1140/epjst/e2012-01697-8

Dahlgren, P. (2018). Media knowledge and trust: the deepening epistemic crisis of democracy. Javnost Public 25, 20-27. doi: 10.1080/13183222.2018. 1418819

Dahlstrom, M. F., and Rosenthal, S. (2018). Third-person perception of science narratives: the case of climate change denial. Sci. Commun. 40, 340-365. doi: $10.1177 / 1075547018766556$

Das, R., and Hodkinson, P. (2019). Tapestries of intimacy: networked intimacies and new fathers' emotional self-disclosure of mental health struggles. Soc. Media Soc. 5. doi: 10.1177/2056305119846488

De Filippi, P. D. F. (2018). Blockchain and the Law: The Rule of Code. Cambridge, MA: Harvard University Press. doi: 10.2307/j.ctv2867sp

Dourish, P., and Cruz, E. G. (2018). Datafication and data fiction: narrating data and narrating with data. Big Data Soc. 5. doi: 10.1177/2053951718 784083

Halavais, A. (2015). Bigger sociological imaginations: framing big social data theory and methods. Inf. Commun. Soc. 18, 583-594. doi: 10.1080/1369118X.2015.1008543

Harford, T. (2014). Big data: a big mistake? Significance 11, 14-19. doi: $10.1111 / j .1740-9713.2014 .00778 . x$

Hartung, T. (2018). Making big sense from big data. Front. Big Data 1:5. doi: 10.1089/big.2012.1503

Hergueux, J., and Jemielniak, D. (2019). Should digital files be considered a commons? Copyright infringement in the eyes of lawyers. Inform. Soc. 35, 198-215. doi: 10.1080/01972243.2019.1616019 
Hill, B. M., and Monroy-Hernández, A. (2013). The remixing dilemma the trade-off between generativity and originality. Am. Behav. Sci. 57, 643-663. doi: $10.1177 / 0002764212469359$

Huntington, H. E. (2016). Pepper spray cop and the American dream: using synecdoche and metaphor to unlock internet memes' visual political rhetoric. Commun. Stud. 67, 77-93. doi: 10.1080/10510974.2015.1087414

Jemielniak, D. (2014). Common Knowledge?: An Ethnography of Wikipedia. Stanford, CA: Stanford University Press. doi: 10.11126/stanford/9780804789448.001.0001

Jemielniak, D. (2020). Thick Big Data: Doing Digital Social Sciences. Oxford: Oxford University Press.

Jemielniak, D., and Przegalinska, A. (2020). Collaborative Society. Cambridge, MA: MIT Press.

Kostakis, V. (2018). In defense of digital commoning. Organization 25, 812-818. doi: $10.1177 / 1350508417749887$

Lakhani, K. R., and Von Hippel, E. (2003). How open source software works. Res. Policy 32, 923-943. doi: 10.1016/S0048-7333(02)00095-1

Latusek, D., and Vlaar, P. W. L. (2018). Uncertainty in interorganizational collaboration and the dynamics of trust: a qualitative study. Eur. Manage. J. 36, 12-27. doi: 10.1016/j.emj.2017.10.003

Lazer, D. M. J., and Radford, J. (2017). Data ex machina: introduction to big data. Annu. Rev. Sociol. 43, 19-39. doi: 10.1146/annurev-soc-060116-053457

Levine, S. S., and Prietula, M. J. (2013). Open collaboration for innovation: principles and performance. Org. Sci. 25, 1414-1433. doi: $10.1287 /$ orsc. 2013.0872

Lis, A., and Stasik, A. K. (2017). Hybrid forums, knowledge deficits and the multiple uncertainties of resource extraction: Negotiating the local governance of shale gas in Poland. Energy Res. Soc. Sci. 28, 29-36. doi: 10.1016/j.erss.2017.04.003

McCarthy, M. T. (2016). The big data divide and its consequences. Sociol. Compass 10, 1131-1140. doi: 10.1111/soc4.12436

Millington, B., and Millington, R. (2015). 'The datafication of everything': toward a sociology of sport and big data. Sociol. Sport J. 32, 140-160 doi: 10.1123/ssj.2014-0069

Milner, R. M. (2013). Pop polyvocality: internet memes, public participation, and the occupy wall street movement. Int. J. Commun. Syst. 7:34. Available online at: https://ijoc.org/index.php/ijoc/article/view/1949
Pechar, E., Bernauer, T., and Mayer, F. (2018). Beyond political ideology: the impact of attitudes towards government and corporations on trust in science. Sci. Commun. 40, 291-313. doi: 10.1177/1075547018763970

Przegalinska, A. (2015). Embodiment. engagement and the strength virtual communities: avatars of second life in decay. Tamara J. Crit. Org. Inquiry $13,48-62$.

Przegalinska, A., Ciechanowski, L., Stroz, A., Gloor, P., and Mazurek, G. (2019). In bot we trust: a new methodology of chatbot performance measures. Bus. Horiz. 62, 785-797. doi: 10.1016/j.bushor.2019.08.005

Rosenfeld, M. (2018). "Are tinder and dating apps changing dating and mating in the USA?," in Families and Technology, ed Van Hooksusan Jennifer King (Cham: Springer), 103-117. doi: 10.1007/978-3-31995540-7_6

Samantray, A., and Pin, P. (2019). Credibility of climate change denial in social media. Palgrave Commun. 5:127. doi: 10.1057/s41599-0190344-4

Shaw, A., and Hargittai, E. (2018). The pipeline of online participation inequalities: the case of wikipedia editing. J. Commun. 68, 143-168. doi: 10.1093/joc/ jqx003

Silvestri, L. (2015). Mortars and memes: participating in pop culture from a war zone. Media War Conflict 9, 27-42. doi: 10.1177/1750635215 611608

Strasser, B. J., Baudry, J., Mahr, D., Sanchez, G., and Tancoigne, E. (2019). "Citizen Science"? Rethinking science and public participation. Sci. Technol. Stud. 32, 52-76. doi: 10.23987/sts.60425

Vigen, T. (2015). Spurious Correlations. New York, NY: Hachette Books.

Conflict of Interest: The author declares that the research was conducted in the absence of any commercial or financial relationships that could be construed as a potential conflict of interest.

Copyright (c) 2020 Jemielniak. This is an open-access article distributed under the terms of the Creative Commons Attribution License (CC BY). The use, distribution or reproduction in other forums is permitted, provided the original author(s) and the copyright owner(s) are credited and that the original publication in this journal is cited, in accordance with accepted academic practice. No use, distribution or reproduction is permitted which does not comply with these terms. 